\title{
Changes in the prevalence and biofilm formation of Haemophilus influenzae and Haemophilus parainfluenzae from the respiratory microbiota of patients with sarcoidosis
}

\author{
Urszula Kosikowska ${ }^{1 *}$, Paweł Rybojad², Dagmara Stępień-Pyśniak³ ${ }^{3}$ Anna Żbikowska ${ }^{4}$ and Anna Malm
}

\begin{abstract}
Background: Healthy condition and chronic diseases may be associated with microbiota composition and its properties. The prevalence of respiratory haemophili with respect to their phenotypes including the ability to biofilm formation in patients with sarcoidosis was assayed.
\end{abstract}

Methods: Nasopharynx and sputum specimens were taken in 31 patients with sarcoidosis (average age $42.6 \pm 13$ ), and nasopharynx specimens were taken in 37 healthy people (average age $44.6 \pm 11.6$ ). Haemophili were identified by API-NH microtest and by the matrix-assisted laser desorption/ionization time-of-flight mass spectrometry (MALDI-TOF MS) system. Biofilm was visualised by crystal violet staining and confocal scanning laser microscopy (CSLM). The statistical analysis was performed with Statgraphics Plus for Windows.

Results: In total, 30/31 patients with sarcoidosis and 31/37 healthy people were colonized by Haemophilus influenzae (6/30 vs. 1/31) and Haemophilus parainfluenzae (28/30 vs. 31/31) in the nasopharynx. The overall number of nasopharyngeal haemophili isolates was 59 in patients with sarcoidosis and 67 in healthy volunteers (H. influenzae 6/59 vs. 1/67, $P=0.05 ; H$. parainfluenzae $47 / 59$ vs. 65/67, $P=0.0032$ ). Moreover, the decreased number of $H$. parainfluenzae biofilm-producing isolates was shown in nasopharyngeal samples in patients with sarcoidosis as compared to healthy people $(19 / 31$ vs. 57/65, $P=0$. 006), especially with respect to isolates classified as strong and very strong biofilm-producers (8/31 vs. 39/65, $P=0.002)$.

Conclusions: The obtained data suggest that the qualitative and quantitative changes within the respiratory microbiota concerning the overall prevalence of $\mathrm{H}$. influenzae together with the decreased number of $\mathrm{H}$. parainfluenzae strains and the decreased rate of $\mathrm{H}$. parainfluenzae biofilm-producing isolates as compared to healthy people may be associated with sarcoidosis,

Keywords: Sarcoidosis, Respiratory microbiota, Haemophilus parainfluenzae, Haemophilus influenzae, Biofilm

Abbreviations: Am, Ampicillin; AmC, Amoxycillin/clavulanate; Caz, Ceftazidime; CRP, C-reactive protein; CSLM, Confocal scanning laser microscopy; CT, Computed tomography; Ctx, Cefotaxime; CV, Crystal violet; FEV 1 , Forced Expiratory Volume/one second; FVC, Forced Vital Capacity; HAEM, Haemophilus-chocolate-agar; HTM, Haemophilus Test Medium; HTMS, Haemophilus-Test-Medium-Supplement; MALDI-TOF MS, Matrix-assisted laser desorption/ionization time-of-flight (Continued on next page)

\footnotetext{
* Correspondence: urszula.kosikowska@umlub.pl

${ }^{1}$ Department of Pharmaceutical Microbiology with Laboratory for

Microbiological Diagnostics, Medical University of Lublin, Chodzki Str. 1,

20-093 Lublin, Poland

Full list of author information is available at the end of the article
}

\section{) Biomed Central}

(C) 2016 The Author(s). Open Access This article is distributed under the terms of the Creative Commons Attribution 4.0 International License (http://creativecommons.org/licenses/by/4.0/), which permits unrestricted use, distribution, and reproduction in any medium, provided you give appropriate credit to the original author(s) and the source, provide a link to the Creative Commons license, and indicate if changes were made. The Creative Commons Public Domain Dedication waiver (http://creativecommons.org/publicdomain/zero/1.0/) applies to the data made available in this article, unless otherwise stated. 
(Continued from previous page)

mass spectrometry; MDR, Multidrug-resistant; MIC, Minimal inhibitory concentration; NP, Nasopharynx; Sam, Ampicillin/

sulbactam; SP, Sputum; Sxt, Trimethoprim/sulfametoxazole; Te, Tetracycline; TSB, Tripticasein-Soy-Broth; TSB +

HTMS, Tripticasein-Soy-Broth supplemented with Haemophilus-Test-Medium-Supplement

\section{Background}

Sarcoidosis is a chronic and enigmatic multisystem disease involving the lung, heart and the lymphatic system $[1,2]$. The etiology of sarcoidosis is not likely to be due to any infections, but rather to an exaggerated and aberrant immune response of genetically susceptible individuals to unidentified antigens, including microorganisms, or several organic and inorganic substances [1-4].

Understanding the role of microbiota composition is a new frontier of human biology and the contemporary direction in the investigation of physiological or pathological phenomena of health or diseases [5-7]. Qualitative and quantitative shifts or perturbation in the microbiota can lead to the development of diseases. Microbiota monitoring and modification may be useful for determination of health, thus providing new means of protection and/or of intervention, and data interpretation [8-10]. The microbiota components predominantly colonizing the respiratory mucosa without causing any disease symptoms can occasionally cause respiratory infections. Besides possible positive or negative interactions between commensals and pathobionts as well as other potential pathogens, microbiota can play an important role for the human host organism in preventing of respiratory and invasive infections [11]. Additionally, microbiota disturbance can contribute to acquisition and carriage of pathogens, can predispose to viral co-infection, especially in people with an immature or damaged immune system.

The human-restricted respiratory tract microbiota representatives are Haemophilus influenzae with significant pathogenicity and opportunistic commensal $H$. parainfluenzae [12, 13]. They may be etiologic agents of invasive or opportunistic diseases [14-16]. H. influenzae, both the encapsulated (mainly serotype b - Hib) and non-encapsulated (nontypeable $H$. influenzae - NTHi) strains have also been associated as potential pathogens with chronic or recurrent and invasive diseases (e.g. bacteremia or sepsis, otitis media, chronic bronchitis, and community-acquired pneumonia) often reported in children and rarely in adults. $H$. parainfluenzae, as an opportunistic bacteria, less often reported as an etiologic agent of infectious diseases, may cause systemic or other respiratory infections (e.g. epiglottitis, meningitis, bacteremia or sepsis, bronchitis, chronic obstructive pulmonary disease, and infective endocarditis).

The human microbiota is a reservoir of opportunistic and potential pathogens (pathobionts), including haemophili, living mainly in a diverse community of biofilm
[17-19]. Biofilm as a structure of microbial community enveloped in a polymeric matrix and adhered to both natural and synthetic surfaces may be regarded as a phenotypic adaptation and protective or pathogenic factor in many infections, depending on the condition [11, 20-22]. It was found to be a form of microbial life important both in colonization and in chronic and recurrent or acute diseases such as otitis media and pneumonia caused by NTHi species [17]. Biofilm is estimated to be involved in about $65 \%$ of human infections with bacterial etiology [23]. Adhesive properties, as well as biofilm formation by microoorganisms together with its intrinsic antimicrobial resistance, exopolysaccharide production and quorum sensing are factors allowing for adaptation to host organism [20]. Both $H$. influenzae and $H$. parainfluenzae have been found to be a biofilm-forming bacteria.

The objectives of the present study were: the analysis of the correlations of diagnostic results in patients with sarcoidosis based on simple regression, haemophili isolation in nasopharyngeal and sputum specimens, antimicrobial resistance determination in $H$. influenzae and $H$. parainfluenzae clinical isolates, biofilm production by clinical isolates of these species together with the analysis of its structure.

\section{Methods}

\section{Patients}

A group of 31 adult patients (average age $42.6 \pm 13$ ) with a suspicion of sarcoidosis who were diagnosed in 2011 at the Chair and Department of Thoracic Surgery (Medical University of Lublin, Poland), participated in the study. The selection criterion was sarcoidosis, which was diagnosed with clinical findings suggesting an incidence of this disease. Patients were directed for diagnosis because of radiological findings such as: lymphadenectomy or tumour of mediastinum, or the presence of small nodules and infiltrations in the lung parenchyma, sclerosis, thickening or fibrosis discovered in CT scans. Multivariable demographic, clinical, radiographic and histological data were collected on the basis of the patients' questionnaires and information protocol.

All patients were diagnosed by means of bronchoscopy, mediastinoscopy or/and lung biopsy. Before the procedure blood samples were collected for standard blood tests (basic metabolic panel and complete blood count). The obtained tissue samples were evaluated by the same pathomorphologist. The histopathological findings were usually described as tuberculosis like granulation which 
could be considered as sarcoidosis in accordance with clinical changes.

A control group of 37 healthy volunteers (average age $44.6 \pm 11.6)$ who agreed to participate in the survey was also included. They did not suffer from respiratory infections and had not received an antimicrobial therapy for at least three months prior to the examination or had not been admitted to hospital for at least two years.

Written informed consent for participation was obtained from people who agreed to take part in the study and filled out the survey. The Ethics Committee of the Medical University of Lublin approved study protocol (KE-0254/75/2011).

\section{Microbiological processing of haemophili isolates}

A total of 31 nasopharyngeal swabs and 31 sputum specimens were taken from patients with sarcoidosis on the day of hospitalization or a day after. Additionally, 37 nasopharyngeal specimens were collected from healthy people.

After incubation $\left(48 \mathrm{~h}, 35 \pm 2{ }^{\circ} \mathrm{C}, 5 \% \mathrm{CO}_{2}\right)$ the colonies with morphological differences were identified independently on selective HAEM-medium (Haemophilus-chocolate-agar, bioMérieux, France). The growth of bacteria in the form of individual colonies or from abundant to very abundant number of morphologically different colonies on Chocolate agar was observed. Initially biochemical identification and biotyping of 192 Gram-negative isolates (125 - from patients with sarcoidosis and 67 - from healthy people) was carried out using the API-NH microtest (bioMérieux). The phenotypes of haemophili isolates were differentiated based on various observable properties in the growth morphology (e.g. the shape and size of the colony, smooth or rough surface, texture, colony elevation), on a set of biochemical reactions (according to API NH results) and antimicrobial susceptibility results. API-NH is a standardized system for the identification of Neisseria, Haemophilus (and related genera) and Moraxella (B.) catarrhalis, which uses microtests and a specially adapted database. Next, for the species differentiation the matrix-assisted laser desorption/ionization time-of-flight mass spectrometry (MALDI-TOF MS, Bruker Daltonik, Germany) system was used according to the procedure described earlier [24]. Software used for data acquisition was MALDI-Biotyper 3.0 (Bruker Daltonik) software. The species which were not identified as $H$. influenzae or $H$. parainfluenzae were classified as other Haemophilus spp.

Antibiotic sensitivities were determined by the disc diffusion method using Haemophilus-Test-Medium (HTM, Oxoid) according to [25]. Direct colony suspensions standardized to 0.5 McFarland standard were prepared using colonies from an overnight HAEM incubation $\left(35{ }^{\circ} \mathrm{C}, 5 \% \mathrm{CO}_{2}\right)$. H. influenzae ATCC10211 was used to verify the growth of bacteria on HTM medium. Different discs with antimicrobial agents (BD
$\mathrm{BBL}^{\mathrm{p}}{ }^{\mathrm{N}}$, Becton Dickinson and Company, USA) namely ampicillin $10 \mu \mathrm{g}$, amoxicillin/clavulanate $20 / 10 \mu \mathrm{g}$, ampicillin/sulbactam $10 / 10 \mu \mathrm{g}$, cefuroxime $30 \mu \mathrm{g}$, cefotaxime $30 \mu \mathrm{g}$, ceftazidime $30 \mu \mathrm{g}$, imipenem $10 \mu \mathrm{g}$, aztreoname $30 \mu \mathrm{g}$, azithromycin $15 \mu \mathrm{g}$, tetracycline $30 \mu \mathrm{g}$, trimethoprim/sulfamethoxazole $1.25 / 23.75 \mu \mathrm{g}$, ciprofloxacin $5 \mu \mathrm{g}$ were used. Resistance $(\mathrm{R})$ zone diameter interpretative criteria were $\leq 18 \mathrm{~mm}$ for ampicillin, $\leq 19 \mathrm{~mm}$ for amoxicillinclavulanate and ampicillin-sulbactam, $\leq 16 \mathrm{~mm}$ for cefuroxime, $\leq 25 \mathrm{~mm}$ for cefotaxime and ceftazidime, $\leq 15 \mathrm{~mm}$ for imipenem, $\leq 25 \mathrm{~mm}$ for aztreoname, $\leq 11 \mathrm{~mm}$ for azithromycin, $\leq 25 \mathrm{~mm}$ for tetracycline, $\leq 10 \mathrm{~mm}$ for trimethoprim/ sulfamethoxazole, $\leq 20 \mathrm{~mm}$ for ciprofloxacin, according to [25]. Multidrug-resistant (MDR) isolates were defined as having resistance to at least three different classes of antimicrobials. Beta-lactamase activity was screened by Penmicrotest (part of API-NH strip) and confirmed with a nitrocefin-based test (Cefinase ${ }^{\mathrm{Tm}}$-Discs, BD $\mathrm{BBL}^{\mathrm{Tm}}$ ) recommended for testing haemophili [25]. Then, E-test strips (bioMérieux) for a determination of susceptibility on the basis of the minimal inhibitory concentration of ampicillin $\left(\mathrm{MIC}_{\mathrm{Am}}\right)$ were used. The MIC criterion, defined as the lowest concentration of the antimicrobial agent that prevents visible growth of the microorganism, for ampicillin-resitant haemophili was $\geq 4 \mu \mathrm{g} / \mathrm{ml}[25]$.

\section{Biofilm detection}

Biofilm formation was examined during the stationary culture in vitro in 24-well polystyrene microplates (24 F-Well Microplates, Thermo Scientific ${ }^{\mathrm{Tm}}$ Nunc $^{\mathrm{Tw}}$, Denmark) using a $0.1 \%$ crystal violet (CV) stain as previously described [26]. The Tripticasein Soy Broth (TSB, Biocorp, Poland) supplemented with Haemophilus Test-Medium Supplement (HTMS, Oxoid) designated as TSB + HTMS was used. Overnight cultures were diluted in TSB + HTMS-medium and standardized at $570 \mathrm{~nm}$ with an initial optical density of $\mathrm{OD}_{570} \sim 0.08 \pm 0.02(\sim 0.5$ McFarland-standard $)$ using a microplate reader ELx800 (BioTek Inc., USA). Next, $500 \mu \mathrm{l}$ of the microbial suspension was inoculated for each well and incubated $\left(35{ }^{\circ} \mathrm{C}, 24 \mathrm{~h}, 5 \% \mathrm{CO}_{2}\right)$. The growth of haemophili was assessed by measuring the $\mathrm{OD}_{570}$. Nonadherent cells were removed by rinsing the wells with sterile water. The biofilm was detected with $\mathrm{OD}_{570}$ according to the method based on staining with $500 \mu \mathrm{l} 0.1 \% \mathrm{CV}$. Each isolate was tested in triplicate in three series. TSB + HTMS without bacteria was incubated under the same conditions and served as blank control.

Haemophili were classified as biofilm-producers as described elsewhere [26]. The experiments were performed in triplicate and the results were averaged. For the purposes of a detailed analysis of the obtained results the classification of biofilm producers was introduced on the basis of criteria proposed by Stepanović et al. [27] and modified by Kosikowska et al. [26]. They defined the 
cut-off an optic density $\mathrm{OD}\left(\mathrm{OD}_{\mathrm{c}}\right)$ for the microtiterplate test as three standard deviations above the mean OD of the negative control. The bacteria were classified as follows: $\mathrm{OD} \leq \mathrm{OD}_{\mathrm{c}}$ - non-producers (category 0 ); $\mathrm{OD}_{\mathrm{c}}<\mathrm{OD} \leq 2 \times \mathrm{OD}_{\mathrm{c}}$ - weak producers (category 1); $2 \times \mathrm{OD}_{\mathrm{c}}<\mathrm{OD} \leq 4 \times \mathrm{OD}_{\mathrm{c}}-$ moderate producers (category 2); $4 \times \mathrm{OD}_{\mathrm{c}}<\mathrm{OD} \leq 8 \times \mathrm{OD}_{\mathrm{c}}-$ strong producers (category 3), $8 \times \mathrm{OD}_{\mathrm{c}}<\mathrm{OD}$ - very strong producers (category 4). $\mathrm{OD}_{\mathrm{c}}$ was $0.1 \pm 0.02$ in our experiments. Additionally, $H$. influenzae ATCC10211, $H$. parainfluenzae ATCC7901, $H$. parainfluenzae ATCC33392 and $H$. parainfluenzae ATCC51505 reference strains were used as biofilm producers. All tests were carried out three times and the results were averaged.

To visualize $H$. influenzae and $H$. parainfluenzae biofilm formation in a $24 \mathrm{~h}$ culture in 24-well polystyrene microplates, the inverted microscope Axiovert 200 M equipped with LSM5 Pascal Head (Carl Zeiss, Germany, with magnification 200x) was used. To obtain images of the biofilm, cultures were stained with Bacterial Live/Dead BacLight ${ }^{\mathrm{m}}$-L7012-kit (Invitrogen, USA) accordingly to the manufacturer's procedure. Biofilm was stained with Live/Dead L7012 kit with two components, Syto9 and propidium iodide (PI), which are nucleic acid stains. The Syto9 stain penetrates through the intact and damaged cell wall, intercalates into DNA, and emits green fluorescence (detection of both live and dead bacteria). The PI stain diffuses only across the dead and damaged cell wall, intercalates into DNA and emits red fluorescence (detection of dead bacteria). The use of a combination of these two dyes is that PI displaces Syto9 (it had a higher affinity) reducing its fluorescence. Thus, the bacteria with intact cell membranes stain fluorescent green, whereas with damaged cell membranes stain fluorescent red. Biofilm formation by $7 \mathrm{H}$. influenzae and $18 \mathrm{H}$. parainfluenzae randomly selected clinical isolates taken in patients with sarcoidosis was screened using confocal microscopy. The thickness of biofilm $(\mu \mathrm{m})$ and measurement area covered by biofilm (\%), content of live cells (\%) and biofilm area covered by live cells (\%) were detected.

Overnight cultures were standardized in TSB + HTMSmedium. Then $500 \mu \mathrm{l} /$ well of cultures was added (for each strain in quadruplicate). After incubation $\left(35^{\circ} \mathrm{C}, 24 \mathrm{~h}, 5 \%\right.$ $\mathrm{CO}_{2}$ ) the content of the wells was removed and each well was washed three-four times with $0.85 \% \mathrm{NaCl}$. Then, $500 \mu \mathrm{l} /$ well of $0.85 \% \mathrm{NaCl}$ was added and then stained with $1.5 \mu$ l of Live/Dead-kit solution. Microphotographs were taken in the green and/or red channel in a Confocal Laser Scanning Microscope LSM5-PASCAL (CLSM; Carl Zeiss, Germany) after incubation for $15 \mathrm{~min}$ in the dark at room temperature. This experiment was repeated twice.

The planimetric measurement of the biofilm was performed based on the microphotographs taken at $50 \times$ or
$200 \times$ magnification in a two-dimensional scan (2D). Biofilm parameters were calculated using Image J-1.43e software (Wayne Rasband, National Institutes of Health, USA). A three-dimensional (3D) image of biofilm was reconstructed using the CLSM (200× magnification).

\section{Statistical analysis}

The statistical analysis was performed with Statgraphics Plus for Windows, Version 4.1 (Statistical Graphics Corp. 1999, Statpoint Technologies, Inc. Warrenton, Virginia, USA). To assess the relationship between the variables a simple regression analysis was used. The aim of the statistical analysis was preliminary determination of the relationship between individual factors and the dependent variables. The relationship between age/gender and different clinical manifestations and laboratory findings were studied. The hypotheses were raised: $\mathrm{H}_{0}$ - there is no association between age/gender and different clinical manifestations and laboratory findings, and $\mathrm{H}_{1}$ - there is an association between age/gender and different clinical manifestations and laboratory findings. Quantitative variables were presented as mean ( \pm standard deviation, SD) and median values. In some studies Fisher's test was evaluated. The level of $P<0.05$ was usually considered as statistically significant.

\section{Results}

\section{Characteristics of patients}

The main characteristics of patients with sarcoidosis are summarized in Table 1. Demographic and clinical data were obtained from the patients' files and based on a questionnaire conducted for the presented variables. "Fatigue" was self reported as being unable to go any further. Susceptibility to "fatigue" was associated with a short walk on a flat surface, or with stair walk to the first or second floors. Symptoms such as shortness of breath, wheezing, cough, expectoration, hypertension, coronary artery disease, allergy, asthma, and recurrent infections ( $\geq 3$ /year) were also considered. Almost $26 \%$ of the patients with sarcoidosis showed recurrent infections in childhood and had other symptoms such as anaemia, celiac disease, or endocrinological disorders. Some of them had two parallel disorders, for example hypertension and coronary artery disease (about $13 \%$ ), and/or allergy (about $10 \%$ ).

There was a positive correlation $(P<0.1)$ between gender and a tumor of the lung/mediastinum $(\mathrm{c}=0.4)$ or fluid in the pleural cavity $(\mathrm{c}=0.32)$ in patients with sarcoidosis (Table 2). These changes mostly occurred in males rather than in females. A positive correlation was demonstrated between gender and CRP (C-reactive protein; $P=0.01, \mathrm{c}=$ 0.44 ), and in elderly patients between the disease and visible changes (e.g. sclerosis, thickening or fibrosis) in the imaging diagnostics of the chest $(P<0.1, \mathrm{c}=0.34-0.45)$. A negative 
Table 1 Baseline clinical characteristics, laboratory findings, and predisposing factors in the group of patients with sarcoidosis

\begin{tabular}{ll}
\hline Variable & $\begin{array}{l}\text { No. of cases/ (\%) or } \\
\text { No. of patients average } \pm \text { SD } \\
\text { or range }\end{array}$ \\
&
\end{tabular}

Gender

Female
Male

Age (years)

Tobacco smoke

Active

Secondary

Area of residence

Rural
Urban

Healthy condition

Shortness of breath, wheezing

Cough

Expectoration

Fatigue:

a short walk $(n=1)$

$1^{\text {st }}$ floor $(n=4)$

$2^{\text {nd }}$ floor $(n=17)$

$13 / 31$

$18 / 31$

41.9

24-64

58.1

$42.6 \pm 13.0$

$9 / 31$

29.0

20/31

64.5

$15 / 31$

48.4

$16 / 31$

51.6

Hypertension, coronary artery disease

Allergy

$12 / 31$

38.7

$16 / 31$

51.6

$4 / 31$

12.9

22/31

71.0

$1 / 22$

$4 / 22$

$17 / 22$

$4 / 31$

$3 / 31$

$1 / 31$

$1 / 31$

$8 / 31$

$8 / 31$

$2 / 31$

Tuberculosis

Laboratory findings

FVC (ml)

2740-6200

$\mathrm{FEV}_{1}(\mathrm{ml})$

$\mathrm{FEV}_{1} / \mathrm{FVC} \%$

$\mathrm{pH}$

$$
\mathrm{pO}_{2}(\mathrm{mmHg})
$$

$\mathrm{pCO}_{2}(\mathrm{mmHg})$

Saturation (\%)

lgG (g/l, reference: 7.0-16.0)

IgM (g/l, reference: 0.4-2.3)

IgA (g/l, reference: 0.7-4.0)

CRP (mg/l, reference: 0.0-5.0):

$0.0-5.0(n=25)$

$5.1-80.48(n=6)$
$1600-5050$

$58-95$

$7.35-7.49$

$63.2-108$

$32.8-49.1$

90.9-97.3

$7.1-21.6$

$0.28-3.54$

$0.51-6.9$

$0.51-80.48$

$0.51-4.15$

$5.8-80.48$
Table 1 Baseline clinical characteristics, laboratory findings, and predisposing factors in the group of patients with sarcoidosis (Continued)

\begin{tabular}{|c|c|c|}
\hline Changes in $\mathrm{CT}$ scan & $30 / 30$ & 100 \\
\hline Changes in X-ray & $19 / 20$ & 95 \\
\hline $\begin{array}{l}\text { Changes observed during } \\
\text { bronchofiberoscopy }\end{array}$ & $14 / 17$ & 82.4 \\
\hline \multicolumn{3}{|c|}{$\begin{array}{l}\text { Data were presented as: No. of positive samples/No. of examinations or value } \\
\text { range; mean } \pm \text { SD } \\
\text { Abbreviations: } C T \text { computed tomography, } C R P C \text {-reactive protein, } F E V \text {, forced } \\
\text { expiratory volume in one second, } F V C \text { forced vital capacity, } \operatorname{lgA}, \operatorname{lgM} M, \lg G \\
\text { immunoglobulin } A, M, G, N P \text { nasopharynx, SP sputum; susceptibility to "fatigue" } \\
\text { was associated with a short walk on a flat surface, or with stair walk to the first or } \\
\text { second floors. "Fatigue" was self reported as being unable to go any further }\end{array}$} \\
\hline
\end{tabular}

correlation between age and $\operatorname{IgM}(P<0.1, \mathrm{c}=-0.4)$ values was detected. Besides, changes in levels of IgG and IgA immunoglobulins were observed.

\section{The prevalence of haemophili-positive clinical samples}

In total, 30/31 (96.8\%) patients with sarcoidosis were colonized by $H$. influenzae and/or $H$. parainfluenzae. $H$. influenzae was isolated in 14/30 (46.7 \%) patients - in 1/ 14 (7.1\%) only in nasopharynx, in 8/14 (57.1\%) only in the sputum and in 5/14 (35.7\%) patients in both samples (Fig. 1a). H. parainfluenzae was isolated in 30/30 (100 \%) patients - in 2/30 (6.7\%) only in nasopharynx, in $2 / 30(6.7 \%)$ only in the sputum and in $26 / 30$ (86.6 \%) cases in both samples (Fig. 1b). The co-existence of $H$. influenzae and $H$. parainfluenzae was found in $14 / 30$ (46.7\%) patients.

In comparison, nasopharynx in 31/37 (83.8 \%) of healthy people was colonized by both species: in $1 / 31$ (3.2 \%) - by H. influenzae, in 31/31 (100\%) - by H. parainfluenzae. There were significant differences in the frequency of nasopharynx colonization by $H$. influenzae ( $P$ $=0.05)$, but not by $H$. parainfluenzae $(P=0.49)$ in patients with sarcoidosis and in healthy people.

Negative correlations (a simple regression) were found between $\mathrm{H}$. influenzae presence in the sputum and $\mathrm{O}_{2}$ saturation $(P<0.01, \mathrm{c}=-0.52)$ or easily bleeding capillaries $(P<0.05, \mathrm{c}=-0.53)$, and between $H$. influenzae presence both in the nasopharynx and in the sputum and the sclerotic changes in lung $(P<0.05, \mathrm{c}=-0.4$ and $\mathrm{c}=-0.44$, respectively). Positive correlations were found between $H$. parainfluenzae isolation in the sputum and the presence of fluid in the pleural cavity $(P<0.01, \mathrm{c}=0.56), \mathrm{pH}$ value $(P<0.05, \mathrm{c}=0.39)$, or $\mathrm{O}_{2}$ saturation $(P<0.1, \mathrm{c}=0.32)$ and tuberculosis like findings $(P<0.1, \quad \mathrm{c}=0.35)$. Negative correlations were found between $H$. parainfluenzae isolation in the sputum and FVC (Forced Vital Capacity; $P<0.1, \mathrm{c}=-0.35)$.

\section{Number of haemophili isolates}

From one to six different phenotypes of haemophili were isolated in the nasopharynx and/or in the sputum 
Table 2 Patient characteristics by age and gender correlations with clinical conditions, laboratory findings, and complications

\begin{tabular}{|c|c|c|c|c|c|}
\hline \multirow[t]{2}{*}{ Tests } & \multirow[t]{2}{*}{ Test results } & \multicolumn{2}{|c|}{ Age (years) } & \multicolumn{2}{|l|}{ Gender } \\
\hline & & $P$ value & Correlation & $P$ value & Correlation \\
\hline \multirow[t]{3}{*}{ Clinical manifestation } & Sclerotic changes in lung & 0.84 & 0.04 & 0.64 & 0.09 \\
\hline & Enlargement of the mediastinal lymph nodes & 0.45 & -0.14 & 0.9 & 0.02 \\
\hline & Tuberculosis like findings & 0.23 & 0.23 & 0.23 & 0.23 \\
\hline \multirow[t]{3}{*}{ Chest radiography } & Micronodules & 0.81 & -0.05 & 0.63 & 0.12 \\
\hline & Pulmonary shading/infiltrations & 0.05 & $0.45^{*}$ & 0.28 & -0.26 \\
\hline & Tumor of the lung/mediastinum & 0.36 & 0.22 & 0.08 & $0.4^{*}$ \\
\hline \multirow[t]{3}{*}{ Chest $C T$} & Changes sclerosis/thickening/fibrosis & 0.61 & 0.22 & 0.64 & 0.04 \\
\hline & Lymphadenopathy & 0.06 & $0.34^{*}$ & 0.16 & -0.27 \\
\hline & Fluid in the pleural cavity & 0.44 & 0.15 & 0.09 & $0.32^{*}$ \\
\hline \multirow[t]{3}{*}{ Changes observed during bronchofiberoscopy } & Infiltration of bronchial wall/macrophages & 0.38 & 0.23 & 0.66 & -0.12 \\
\hline & Scraps of bronchial epithelial/mucus & 0.28 & 0.28 & 0.39 & 0.22 \\
\hline & Easy bleeding capillaries & 0.17 & -0.35 & 0.33 & 0.25 \\
\hline \multirow[t]{5}{*}{ Laboratory findings } & $\mathrm{pH}$ & 0.77 & -0.06 & 0.68 & -0.08 \\
\hline & $\lg G(g / l)$ & 0.74 & -0.06 & 0.41 & 0.15 \\
\hline & $\lg M(g / l)$ & 0.25 & $-0.4^{*}$ & 0.27 & -0.2 \\
\hline & $\lg A(g / l)$ & 0.17 & 0.25 & 0.47 & 0.14 \\
\hline & CRP (mg/l) & 0.21 & 0.23 & 0.01 & $0.44^{* *}$ \\
\hline
\end{tabular}

Abbreviations: CT computed tomography, CRP C-reactive protein

The significance levels were marked as: ${ }^{*} P<0.1$, and $\left.{ }^{* *} P<0.05\right)$

samples in each single patient. The growth morphology and biochemical features distinguished phenotypes of isolates. In total, 125 haemophili isolates were found in 62 nasopharyngeal swabs and sputum samples obtained in patients with sarcoidosis. In 30 haemophili-positive nasopharyngeal samples 59/125 (47.2\%) isolates were identified: 6/59 (10.2 \%) as $H$. influenzae, 47/59 (79.7 \%) as H. parainfluenzae and 6/59 (10.2\%) as other Haemophilus spp. In 30 haemophili-positive samples taken in the sputum, 66/125 (52.8\%) isolates were identified: 13/66 (19.7 \%) as $H$. influenzae, 49/66 (74.2\%) as $H$. parainfluenzae and 4/66 (6.1\%) as other Haemophilus spp.

Likewise, in 31 haemophili-positive samples obtained in the nasopharynx of healthy people 67 isolates were identified: 1/67 (1.5 \%) as H. influenzae, 65/67 (97.0\%) as $H$. parainfluenzae, and $1 / 67(1.5 \%)$ as other Haemophilus spp. H. parainfluenzae was the main species isolated from the nasopharynx in both groups. There were statistically significant differences between the number of $H$. influenzae $(P=0.05)$ or $H$. parainfluenzae $(P=0.0032)$ isolates in patients with sarcoidosis and in healthy people.

\section{Biotypes of $\mathrm{H}$. influenzae and $\mathrm{H}$. parainfluenzae isolates}

A total of $19 \mathrm{H}$. influenzae and $96 \mathrm{H}$. parainfluenzae strains isolated from patients with sarcoidosis were assigned to eight biotypes. Biotypes III and VI occurred in $47.4 \%$ and $26.3 \%$ H. influenzae isolates respectively, mainly in the sputum (Table 3). Biotypes I (60.4\%) and II $(30.2 \%)$ constituted most of the $H$. parainfluenzae isolates both in the nasopharynx and in the sputum. For comparison, thedifferences were observed in nasopharyngeal $H$. parainfluenzae biotypes I-IV identified in healthy people and in patients with sarcoidosis (biotype I: $58.5 \%$ vs. $26 \%, P=0.6998$; biotype II: $20 \%$ vs. $16 \%$, $P=0.1864$; biotype III: $12.3 \%$ vs. $5.2 \%, P=1.000$ and biotype IV: $6.2 \%$ vs. $1 \%, P=0.397$, respectively).

\section{Antimicrobials sensitivity of $H$. influenzae and $H$. parainfluenzae isolates}

As shown in Table 4, only 4/19 (21.1 \%) H. influenzae isolates from patients with sarcoidosis were resistant to the antimicrobials - 2/19 (10.5\%) were trimethoprim/ sulfamethoxazole-resistant and 2/19 (10.5 \%) were tetracycline-resistant (Table 4). In contrast, 53/96 (55.2 \%) H. parainfluenzae isolates were resistant to the antimicrobials - 18/96 (18.8\%) were trimethoprim/ sulfamethoxazole-resistant and 15/96 (15.6 \%) were tetracycline-resistant. In addition, 20/96 (20.9 \%) $H$. parainfluenzae isolates were resistant to beta-lactams, including 8/96 (8.3\%) ampicillin-resistant ones.

The presence of nasopharyngeal $H$. parainfluenzae isolates resistant to tetracycline $(4 / 65 ; 6.2 \%)$ and to trimethoprim/sulfametoxazole $(8 / 65 ; 12.3 \%)$ was shown in 


\section{A Haemophilus influenzae}

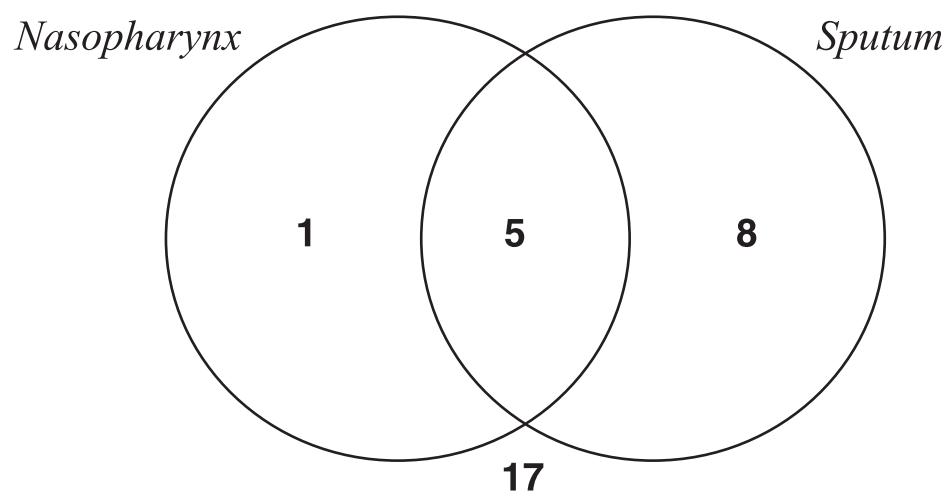

B Haemophilus parainfluenzae

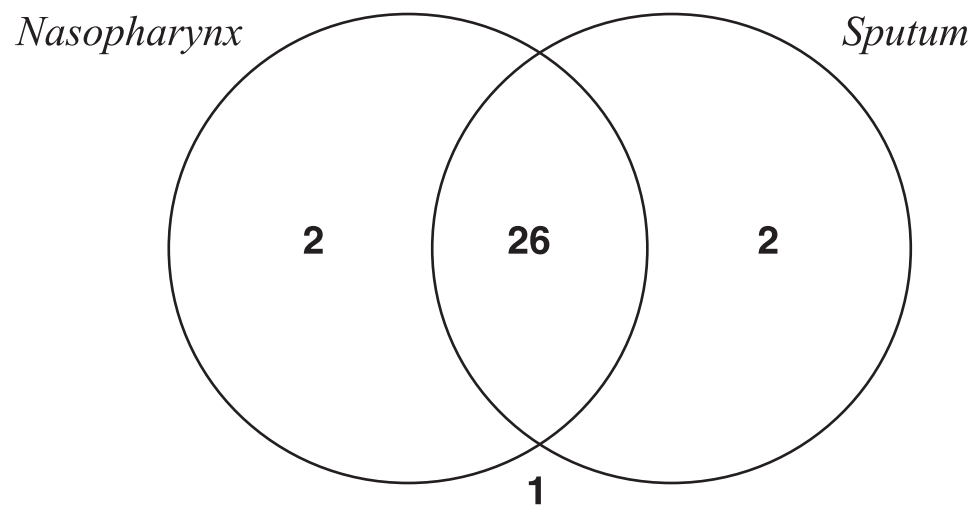

Fig. 1 The prevalence of Haemophilus influenzae (a) and Haemophilus parainfluenzae (b) positive clinical samples in patients with sarcoidosis

healthy people. In addition, 23/65 (35.4\%) isolates were resistant to beta-lactams, including 10/65 (15.4 \%) ampicillin-resistant ones.

The difference in presence of nasopharyngeal $H$. parainfluenzae isolates resistant to tetracycline in patients with sarcoidosis and in healthy people $(19.1 \%$ vs. $6.2 \%, P=0.041$ ) was statistically significant. The differences in resistance to trimethoprim/sulfametoxazole (21.3\% vs. $12.3 \%, P=0.297)$ and to beta-lactams (23.4 \% vs. $35.3 \%, P=0.214$ ), including ampicillin (12.8\% vs. $15.4 \%, P=1.000$ ) were also found, but they were not statistically significant.

The ampicillin-resistant isolates selected in patients with sarcoidosis $\left(\mathrm{MIC}_{\mathrm{Am}} \geq 6 \mu \mathrm{g} / \mathrm{ml}\right)$ were beta-lactamasepositive, and were found within I and III biotypes (Table 5). High MICs for ampicillin were detected in two isolates taken in the nasopharynx $(\mathrm{MIC}=128$ and $>256 \mu \mathrm{g} / \mathrm{ml})$, and in one isolate taken in the sputum $(\mathrm{MIC}=48 \mu \mathrm{g} / \mathrm{ml})$. Among $H$. parainfluenzae isolates, 3/96 (3.1 \%) isolates were resistant to beta-lactams, tetracycline, and trimethoprim/sulfametoxazole (MDR-strains).
Biofilm formation by $H$. influenzae and $H$. parainfluenzae isolates

In total, 69 randomly selected $H$. influenzae and $H$. parainfluenzae isolates (35 - nasopharyngeal, 34 - from the sputum) taken in patients with sarcoidosis were screened for biofilm-production using the $\mathrm{CV}$ method. According to Table 6, 8/12 (66.7 \%) isolates of $H$. influenzae and 39/57 (68.4\%) of $H$. parainfluenzae were found to be biofilmproducers $(P=0.407)$. All $8 / 12(66.7 \%) H$. influenzae isolates were weak-producers, irrespective of the clinical specimens. Among 19 biofilm-forming $H$. parainfluenzae isolates from nasopharynx, the ability to biofilm formation ranged from weak $(11 / 19,57.8 \%)$ to strong $(1 / 19,5.3 \%)$ and very strong $(7 / 19,36.8 \%)$.

Additionally, reference strains were included as biofilmproducers: $H$. influenzae ATCC10211as weak biofilmproducer $\left(\mathrm{OD}_{570}=0.098 \pm 0.05\right), H$. parainfluenzae ATCC 7901 as strong biofilm-producer $\left(\mathrm{OD}_{570}=0.682 \pm 0.07\right)$, and both $H$. parainfluenzae ATCC33392 and $H$. parainfluenzae ATCC51505 as very strong biofilm-producers $\left(\mathrm{OD}_{570}=\right.$ $1.191 \pm 0.04$ and $\mathrm{OD}_{570}=1.026 \pm 0.08$, respectively). 
Table 3 Distribution of Haemophilus influenzae and Haemophilus parainfluenzae biotypes in healthy people and in patients with sarcoidosis

\begin{tabular}{|c|c|c|c|c|}
\hline \multirow{3}{*}{ Biotype } & \multirow{2}{*}{$\begin{array}{l}\text { Healthy people } \\
\text { Nasopharynx }\end{array}$} & \multicolumn{3}{|c|}{ Patients with sarcoidosis } \\
\hline & & \multirow[t]{2}{*}{ Nasopharynx } & \multirow[t]{2}{*}{ Sputum } & \multirow[t]{2}{*}{ Total } \\
\hline & No. (\%) of isolates & & & \\
\hline Haemophilus influenzae & $n=1$ & & $n=19$ & \\
\hline$\|$ & $0(0)$ & $3(15.8)$ & $0(0)$ & $3(15.8)$ \\
\hline III & $0(0)$ & $2(10.5)$ & $7(36.8)$ & $9(47.4)$ \\
\hline $\mathrm{Vl}$ & $1(100)$ & $1(5.3)$ & $4(21.1)$ & $5(26.3)$ \\
\hline VIII & $0(0)$ & $0(0)$ & $2(10.5)$ & $2(10.5)$ \\
\hline Haemophilus parainfluenzae & $n=65$ & & $n=96$ & \\
\hline । & $38(58.5)$ & $25(26.0)$ & $33(34.4)$ & $58(60.4)$ \\
\hline$\|$ & $13(20.0)$ & $15(15.6)$ & $14(14.6)$ & $29(30.2)$ \\
\hline III & $8(12.3)$ & $5(5.2)$ & $1(1.04)$ & $6(6.3)$ \\
\hline IV & $4(6.2)$ & $1(1.04)$ & $0(0)$ & $1(1.04)$ \\
\hline $\mathrm{VI}$ & $1(1.5)$ & $1(1.04)$ & $0(0)$ & $1(1.04)$ \\
\hline VII & $0(0)$ & $0(0)$ & $1(1.04)$ & $1(1.04)$ \\
\hline VIII & $1(1.5)$ & $0(0)$ & $0(0)$ & $0(0)$ \\
\hline
\end{tabular}

In $65 \mathrm{H}$. parainfluenzae isolates obtained from nasopharynx of healthy people, in $57 / 65(87.7 \%)$ isolates the ability for biofilm formation was identified (Table 6). Among 57 biofilm-positive $H$. parainfluenzae isolates 15/ 57 (26.3\%), 3/57 (5.3 \%), 12/57 (21.1\%), and 27/57 (47.4\%) ones were classified as weak, moderate, strong or very strong biofilm-producers, respectively. Significant differences between the ability to biofilm production in nasopharyngeal $H$. parainfluenzae isolates taken in patients with sarcoidosis and in healthy people were shown $(P=$ 0.006). Among biofilm-positive $H$. parainfluenzae isolates taken in cases and in healthy people significant differences were observed between weak biofilm-producers and the group of isolates classified as moderate, strong and very strong biofilm-producers $(P=0.024)$.
Morphometric parameters of biofilm formed by $7 \mathrm{H}$. influenzae and $18 \mathrm{H}$. parainfluenzae isolates taken from the patients with sarcoidosis were assessed by means of CLSM technique (Table 7). The biofilm formed by $H$. influenzae isolates had the thickness of $14.2 \pm 3.5 \mu \mathrm{m}$ and covered $71.6 \pm 5.6 \%$ of the measured area. The content of living cells was from 8.6 to $95.2 \%$ (average 71.6 $\pm 4.4 \%)$ and it was $75.2 \pm 4.8 \%$ in the biofilm area. The biofilm formed by $H$. parainfluenzae isolates had the thickness of $20.02 \pm 4.3 \mu \mathrm{m}$ and covered about $50.6 \pm$ $4.8 \%$ of the measured area. The content of living cells was from 42.8 to $99.9 \%$ (average $80.9 \pm 4.8 \%$ ) and it was about $77.9 \pm 8.98 \%$ in the biofilm area.

The biofilm formed by one of $H$. parainfluenzae nasopharyngeal isolate taken from a patient with sarcoidosis

Table 4 Distribution of antimicrobial resistance in Haemophilus influenzae and Haemophilus parainfluenzae isolates in healthy people and in patients with sarcoidosis

\begin{tabular}{|c|c|c|c|c|c|c|c|c|}
\hline \multirow[b]{2}{*}{ Species } & \multirow[b]{2}{*}{ Place of isolation } & \multicolumn{7}{|c|}{ No. (\%) of resistant isolates } \\
\hline & & Sxt & $\mathrm{Te}$ & Ctx & $\mathrm{Caz}$ & Sam & $\mathrm{AmC}$ & $\mathrm{Am}$ \\
\hline \multicolumn{9}{|l|}{ Healthy people } \\
\hline Haemophilus influenzae $(n=1)$ & Nasopharynx $(n=1)$ & 0 & 0 & 0 & 0 & 0 & 0 & 0 \\
\hline Haemophilus parainfluenzae $(n=65)$ & Nasopharynx $(n=65)$ & $8(12.3)$ & $4(6.2)$ & $4(6.2)$ & $5(7.7)$ & $3(4.6)$ & $1(1.5)$ & $10(15.4)$ \\
\hline \multicolumn{9}{|l|}{ Patients with sarcoidosis } \\
\hline \multirow[t]{2}{*}{ Haemophilus influenzae $(n=19)$} & Nasopharynx $(n=6)$ & $1(16.7)$ & 0 & 0 & 0 & 0 & $1(16.7)$ & 0 \\
\hline & Sputum $(n=13)$ & $1(7.7)$ & $2(15.4)$ & 0 & 0 & 0 & 0 & 0 \\
\hline \multirow[t]{2}{*}{ Haemophilus parainfluenzae $(n=96)$} & Nasopharynx $(n=47)$ & $10(21.3)$ & $9(19.1)$ & $2(4.3)$ & $3(6.4)$ & 0 & 0 & $6(12.8)$ \\
\hline & Sputum $(n=49)$ & $8(16.3)$ & $6(12.2)$ & $1(2.0)$ & $5(10.2)$ & 0 & 0 & $2(4.1)$ \\
\hline
\end{tabular}


Table 5 Distribution of beta-lactamase positive ampicillin-resistant Haemophilus parainfluenzae isolates in patients with sarcoidosis

\begin{tabular}{|c|c|c|c|c|}
\hline \multirow[t]{2}{*}{ Biotype } & \multicolumn{2}{|l|}{ Nasopharynx } & \multicolumn{2}{|l|}{ Sputum } \\
\hline & Resistance profile (No. of isolates) & $\mathrm{MIC}_{\mathrm{Am}}(\mu \mathrm{g} / \mathrm{ml})$ & Resistance profile (No. of isolates) & $\mathrm{MIC}_{\mathrm{Am}}(\mu \mathrm{g} / \mathrm{ml})$ \\
\hline \multirow[t]{4}{*}{ । } & $\operatorname{Am}(1)$ & 24 & AmTe (1) & 4 \\
\hline & AmSxt (1) & $>256$ & AmTe (1) & 48 \\
\hline & AmCtxCazSxt (1) & 8 & & \\
\hline & AmTeSxt (1) & 128 & & \\
\hline \multirow[t]{2}{*}{ III } & AmCtxCazTeSxt (1) & 6 & & \\
\hline & AmTeSxt (1) & 6 & & \\
\hline
\end{tabular}

Abbreviations: Am ampicillin, Caz ceftazidime, Ctx cefotaxime, Te tetracycline, Sxt trimethoprim/sulfametoxazole

Ampicillin breakpoints used for interpretation of minimal inhibitory concentration $\left(\mathrm{MIC}_{\mathrm{Am}}\right.$ ): susceptible $\leq 1 \mu \mathrm{g} / \mathrm{ml}$, intermediate $=2 \mu \mathrm{g} / \mathrm{ml}$ and resistant $\geq 4 \mu \mathrm{g} / \mathrm{ml}$, according to [25]

was revealed by CLSM image (Fig. 2). The biofilm area formed by living (Fig. 2a) and dead (Fig. 2c) cells is presented. The textural parameters were detected as the grey scale intensity of the biofilm formed by live (Fig. 2b) and dead (Fig. 2d) cells.

\section{Discussion}

Several environmental agents interacting with social and genetic factors and including immune responses to microbial components rather than an infection per se have been considered to play a role in the pathogenesis of sarcoidosis $[1,2,4]$. In our study changes in the healthy conditions, in the imaging diagnostics of the chest and in levels of three major immunoglobulins (IgG, IgM and IgA) as well as CRP value with respect to sarcoidosis and the age and gender were shown (Tables 1 and 2). Similar observations were also done by other authors [28-31]. Hiperglobulinemia is frequently observed in patients with sarcoidosis [30]. Changes observed in this group of patients [29, 30] and in elderly people [31] suggested an association between age, race, sex and the immune system's defense as well as microbials presence. According to Buckley et al. [29], in patients with sarcoidosis the increase in IgG was significant in white patients, and the increase in IgM concentration was significant only in black patients, especially in black woman. Cagatay et al. [32] found higher than normal laboratory values for immunoglobulins IgG, IgA and IgM. They have noted that IgG and IgA levels were significantly higher in the group of routinely checked patients without any clinical

Table 6 Distribution of Haemophilus influenzae and Haemophilus parainfluenzae biofilm-producers in patients with sarcoidosis and in healthy people

\begin{tabular}{|c|c|c|c|c|c|}
\hline \multirow{2}{*}{$\begin{array}{l}\text { Category of } \\
\text { biofilm producers }\end{array}$} & \multirow[t]{2}{*}{$\mathrm{OD}_{570}$ range } & \multicolumn{4}{|l|}{ No. (\%) of isolates } \\
\hline & & \multicolumn{2}{|l|}{ Haemophilus influenzae } & \multicolumn{2}{|c|}{ Haemophilus parainfluenzae } \\
\hline \multicolumn{6}{|l|}{ Healthy people } \\
\hline & & \multicolumn{2}{|l|}{ Nasopharynx $(n=1)$} & \multicolumn{2}{|l|}{ Nasopharynx $(n=65)$} \\
\hline Non-producers & 0.0 & \multicolumn{2}{|l|}{$0(0.0)$} & \multicolumn{2}{|l|}{$8(12.3)$} \\
\hline Weak & $0.01-0.24$ & \multicolumn{2}{|l|}{$1(100)$} & \multicolumn{2}{|l|}{$15(23.1)$} \\
\hline Moderate & $0.25-0.48$ & \multicolumn{2}{|l|}{$0(0.0)$} & \multicolumn{2}{|l|}{$3(4.6)$} \\
\hline Strong & $0.49-0.96$ & \multicolumn{2}{|l|}{$0(0.0)$} & \multicolumn{2}{|l|}{$12(18.5)$} \\
\hline Very strong & $\geq 0.97$ & \multicolumn{2}{|l|}{$0(0.0)$} & \multicolumn{2}{|l|}{$27(41.5)$} \\
\hline \multicolumn{6}{|c|}{ Patients with sarcoidosis } \\
\hline & & Nasopharynx $(n=4)$ & Sputum $(n=8)$ & Nasopharynx $(n=31)$ & Sputum $(n=26)$ \\
\hline Non-producers & 0.0 & $1(25.0)$ & $3(37.5)$ & $12(38.7)$ & $6(23.1)$ \\
\hline Weak & $0.01-0.24$ & $3(75.0)$ & $5(62.5)$ & $11(35.5)$ & $9(34.6)$ \\
\hline Moderate & $0.25-0.48$ & $0(0.0)$ & $0(0.0)$ & $0(0.0)$ & $3(11.5)$ \\
\hline Strong & $0.49-0.96$ & $0(0.0)$ & $0(0.0)$ & $1(3.2)$ & $4(15.4)$ \\
\hline Very strong & $\geq 0.97$ & $0(0.0)$ & $0(0.0)$ & $7(22.6)$ & $4(15.4)$ \\
\hline
\end{tabular}

Distribution of biofilm-producers was detected using the crystal-violet (CV) method. The cut-off OD $\left(\mathrm{OD}_{c} ;\right.$ here: $\left.0.1 \pm 0.02\right)$ was defined as three standard deviations

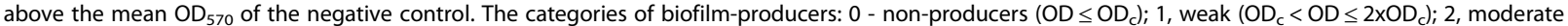
$\left(2 \times O D_{c}<O D \leq 4 \times O D_{c}\right) ; 3$, strong $\left(4 x_{C O D}<O D \leq 8 x_{c}\right) ; 4$, very strong $\left(8 x_{c} D_{c}<O D\right)$ producers, according to [26] 
Table 7 Morphometric parameters of biofilm formed by Haemophilus influenzae and Haemophilus parainfluenzae isolates taken from patients with sarcoidosis

\begin{tabular}{|c|c|c|c|c|}
\hline Haemophili isolates selected from & $\begin{array}{l}\text { Thickness of } \\
\text { biofilm } \pm S D(\mu \mathrm{m})\end{array}$ & $\begin{array}{l}\text { Measurement area covered } \\
\text { by biofilm (\%) } \pm \text { SD }\end{array}$ & $\begin{array}{l}\text { Content of live cells (\%) } \\
\text { in biofilm } \pm \text { SD }\end{array}$ & $\begin{array}{l}\text { Biofilm area covered by } \\
\text { live cells }(\%) \pm S D\end{array}$ \\
\hline & \multicolumn{4}{|c|}{ Haemophilus influenzae } \\
\hline Nasopharynx $(n=3)$ & $11.3 \pm 3.2$ & $68.9 \pm 2.5$ & $58.4 \pm 2.97$ & $66.99 \pm 9.1$ \\
\hline Sputum $(n=4)$ & $16.4 \pm 3.7$ & $73.6 \pm 7.96$ & $81.5 \pm 5.4$ & $81.4 \pm 1.6$ \\
\hline \multirow[t]{2}{*}{ All $(n=7)$} & $14.2 \pm 3.5$ & $71.6 \pm 5.6$ & $71.6 \pm 4.4$ & $75.2 \pm 4.8$ \\
\hline & \multicolumn{4}{|c|}{ Haemophilus parainfluenzae } \\
\hline Nasopharynx $(n=10)$ & $20.5 \pm 4.9$ & $47.1 \pm 5.9$ & $76.8 \pm 4.2$ & $72.5 \pm 12.5$ \\
\hline Sputum $(n=8)$ & $19.4 \pm 3.7$ & $54.95 \pm 3.5$ & $86.0 \pm 5.4$ & $84.6 \pm 4.7$ \\
\hline Total $(n=18)$ & $20.0 \pm 4.3$ & $50.58 \pm 4.8$ & $80.9 \pm 4.8$ & $77.9 \pm 8.98$ \\
\hline
\end{tabular}

Averages morphometric parameters of biofilm formed by Haemophilus influenzae and Haemophilus parainfluenzae isolates was calculated on the basis of data assessed using confocal laser scanning microscopy (CLSM) images after $24 \mathrm{~h}$ incubation
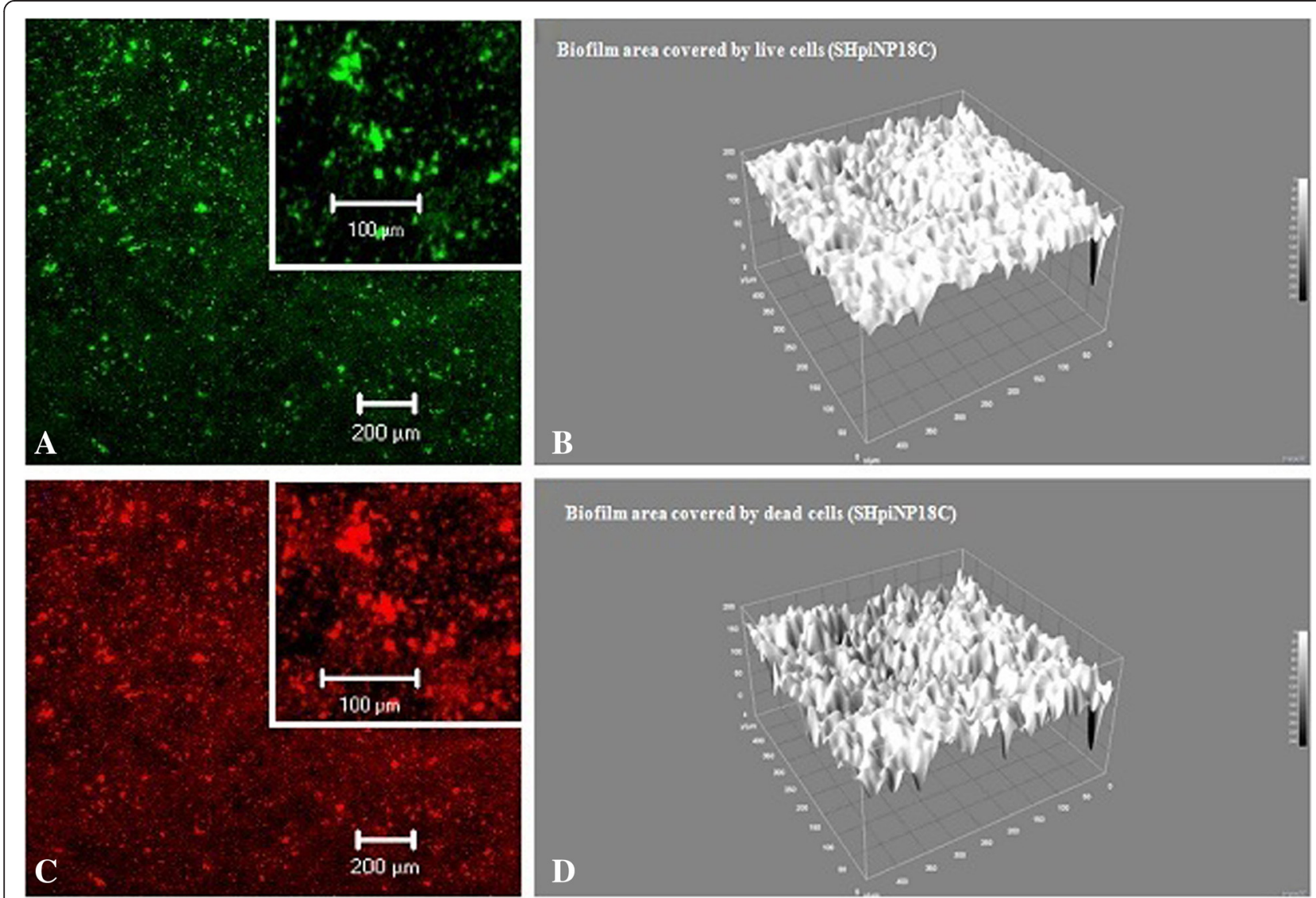

Fig. 2 Biofilm formed by living and dead cells of Haemophilus parainfluenzae SHpiNP18C strain. Expanations: Biofilm formed by living (a, b) and dead (c, d) cells of Haemophilus parainfluenzae SHpiNP18C and detected using two-dimensional (2d: a, c) or three-dimensional (3d: b, d) CLSM image with gray level values varying from 0 to $250(\mathbf{b}, \mathbf{d})$ after $24 \mathrm{~h}$ of incubation. The layer of living cells was located on or between the structures formed by dead cells. The living and dead cells forming biofilm were detected in the green and red canals, respectively, and the structure of the biofilm was shown in XZ plan on the basis of 3D scan 
symptoms and during established the activity of the disease. Drent et al. [33] have identified a high CRP concentration associated with severe fatigue in sarcoidosis.

The human microbiota has multidirectional effects on the host's health and changes in its composition may have important consequences for human pathophysiology and disease development [5, 7, 8, 34]. According to literature, bacterial $16 \mathrm{~S}$ rRNA from $H$. influenzae as well as Moraxella catarrhalis was detected in sarcoid fluid samples [35]. Cantwell's review [3] pointed to the presence of other bacterial species (e.g. Mycobacterium spp., staphylococci, Propionibacterium acnes) in the biopsy of sarcoid tissue, blood, and skin samples taken from patients with sarcoidosis.

According to our results, higher rate of nasopharyngeal colonization by $H$. influenzae, but not by $H$. parainfluenzae $(P=0.05$ vs. $P=0.49)$ was found in patients with sarcoidosis as compared to colonization in healthy people. It suggests that sarcoidosis can be regarded as a factor predisposing for colonization by $H$. influenzae. Besides, $H$. influenzae was frequently found in the sputum samples taken in patients with sarcoidosis even if this bacterial species was absent in the nasopharynx. In our opinion, it suggests the role of $H$. influenzae in the lower respiratory tract colonization and inflammation particularly in chronic diseases, e.g. in patients with sarcoidosis. In the literature [36], it has been documented that a combination of pathogenic mechanisms of bacteria and defects in host defense may allow this species to their migration into the lower respiratory tract. This may result in chronic colonization and/or in acute exacerbations of airway disease.

Despite the high and a similar number of people colonized by $H$. parainfluenzae in the nasopharynx of healthy people and patients with sarcoidosis $(83.8 \%$ vs. $96.8 \%$ ), we observed a decreased number of this species isolates with different phenotypes, differentiated on the basis of growth morphology, biochemical characteristics and biotypes. In 30 patients with sarcoidosis 47 isolates of $H$. parainfluenzae were identified, while in 31 healthy people - 65 isolates of this species. H. parainfluenzae isolates with biotypes I and II were found to occur most frequently, similarly in patients with sarcoidosis and in healthy people (Table 3). As found by other authors [37-39], these biotypes constituted most of $H$. parainfluenzae isolates in patients with other respiratory diseases such as chronic bronchitis or cystic fibrosis.

During our studies we compared the antimicrobial susceptibility of nasopharyngeal $H$. parainfluenzae isolates obtained in patients with sarcoidosis and in healthy people (Table 4). Resistance of these isolates to tetracycline $(P=0.041)$ and trimethoprim/sulfametoxazole $(P=$ $0.297)$ in patients with sarcoidosis was higher compared to that in healthy people. In contrast, resistance to beta- lactams $(P=0.214)$, including ampicillin $(P=1.000)$ was lower in patients with sarcoidosis compared to that in healthy people. These differences may be due to higher consumption of a given group of antimicrobials in a defined population. The growing antibiotic resistance and reduction or elimination their effectiveness is one of the world's most pressing public health problems [40].

Beta-lactam antibiotics are the most widely used antimicrobial agents during treatment of both communityacquired and hospital infections. The resistance to this group of antimicrobials in Haemophilus spp. usually is mediated by the production of beta-lactamases and the presence of altered penicillin-binding protein (PBP) with lowered affinity for these antibiotics as a target site [17, 41]. The ampicillin-resistant, beta-lactamase positive $H$. parainfluenzae isolates from patients with sarcoidosis were found in our studies (Tables 4 and 5). This may have some implications including the possibility to exchange resistance genes within microorganisms [40-45].

According to literature, over the past years many authors detected beta-lactamases mainly in $H$. influenzae and rarely in $H$. parainfluenzae isolates taken from patients with respiratory tract infections as well as from healthy people $[25,26,46]$. It was shown that DNA mutation and rapid multiplication as well as transformation can be important mechanisms in the spread of drug resistance in haemophili, including the ampicillin resistance due to beta-lactamase production $[45,46]$. It seems that especially efficient in transformation were $H$. parainfluenzae cells with a highest ability to develop competence and transfer of resistance genes occurs via free DNA (from dead or lysed cells) during natural transformation from the medium by competent cells. It may explain the acquisition of resistance or resistance gene exchange with other microorganisms. Besides, resistance and reduced susceptibility to beta-lactams mediated by altered PBPs is also important in many bacterial pathogens, including beta-lactamase negative $H$. influenzae [47]. For this reason, there are different events that may contribute to the emerge of resistance: the acquisition of resistance genes (e.g. beta-lactamases) by conjugation or transformation; and inter-species recombination of the ftsI gene [47, 48]. According to Gromkova et al. [46], most efficient in transformation among $H$. parainfluenzae strains was biotype II, followed by biotype I.

It was shown in this paper that $H$. parainfluenzae isolates selected in patients with sarcoidosis compared to isolates selected in healthy people had a lower ability for biofilm production (Table 6). It is possible that a reduction in the number of $H$. parainfluenzae strains capable of biofilm formation may contribute to an increased colonization by certain opportunistic pathogens like $H$. influenzae (the present results) or by other bacteria $[3,4]$. The CLSM technique revealed that biofilms formed in 
vitro by $H$. parainfluenzae and $H$. influenzae isolates taken from patients with sarcoidosis (Table 7, Fig. 2) had high content of live cells (average 72 to $81 \%$ ), suggesting the possibility of bacterial persistence and dispersal in vivo.

Biofilm may be regarded as a pathogenic or protective factor depending on the conditions [18, 21]. Nontypeable $H$. influenzae [NTHi] biofilms were observed for both bacteria colonizing the tissue of human, as an etiologic agent which causes the infection or exacerbation of chronic respiratory diseases [49-51]. On the other hand, Clancy and Dunkley [52] showed that oral NTHi could enhance the mucosal protection and prevent exacerbations of a chronic obstructive pulmonary disease.

On the basis of our results we propose, that haemophili, mainly $H$. influenzae and $H$. parainfluenzae, would be microorganisms indicative in respiratory microbiota changes as well as healthy condition in patients with chronic diseases. We observed higher frequency of $H$. influenzae colonization in patients with sarcoidosis compared to healthy people $(P=0.05)$. All $H$. influenzae isolates were weak- or non-biofilm producers independently to source of isolation and peoples' health condition. Moreover, despite the high prevalence of $H$. parainfluenzae in the nasopharynx of people from both studied groups $(P=0.49)$, less number of isolates of this species obtained in nasopharyngeal samples in patients with sarcoidosis as compared to healthy people were classified as biofilm-producers $(61.3 \%$ vs. $87.7 \%, P=0.006$ ), especially as strong and very strong biofilm-producers ( $25.8 \%$ vs. $60 \%, P=0.002)$.

\section{Conclusions}

The obtained results suggest that sarcoidosis, associated with many different factors, may be partially due to the respiratory microbiota condition. This is the first study describing qualitative and quantitative changes in the respiratory microbiota in patients with sarcoidosis with the respect to $H$. influenzae and $H$. parainfluenzae biotypes and their ability for biofilm formation. The question whether the biofilm formed by these bacterial species is a causative or just a protective factor in recurrent or chronic diseases, e.g. sarcoidosis, requires further studies.

\section{Acknowledgments}

We thank the director of the Department of Epizootiology and Clinic of Infectious Diseases, Faculty of Veterinary Medicine, University of Life Sciences in Lublin, Stanisław Winiarczyk, for his support. The authors are indebted to Beata WojtysiakDuma for performing serological tests, Mr Tomasz Piersiak for his participation in CLSM study, and Dorota Pietras-Ożga for her participation in MALDI-TOF MS study.

\section{Funding}

No external funding was obtained for this case report.

\section{Authors' contributions}

UK conceived, designed and coordinated the study, collected and identified haemophili species, measured biofilm, analysed the data, wrote and drafted the manuscript. PR collected patients' protocols and the nasopharynx and sputum specimens. DSP contributed to collecting specimens and identified haemophili isolates using MALDI-TOF MS system and manuscript review. AŻ statistically analysed the data, AM analysed the data and critically revised the manuscript. All co-authors read and approved the final manuscript.

\section{Competing interests}

The authors declare that they have no competing interests.

\section{Consent for publication}

Not applicable.

\section{Ethics approval and consent to participate}

All procedures performed in studies were in accordance with the ethical standards of the institutional research committee. The Ethics Committee of the Medical University of Lublin approved study protocol (KE-0254/75/2011). Written informed consent for participation was obtained from people who agreed to take part in the study at the time of data collection and filled out the survey. Respondents were assured of confidentiality. The study investigators were the only persons allowed to inform and counsel the volunteers after the results were obtained.

\section{Author details}

'Department of Pharmaceutical Microbiology with Laboratory for Microbiological Diagnostics, Medical University of Lublin, Chodzki Str. 1, 20-093 Lublin, Poland. ²Department of Thoracic Surgery, Medical University of Lublin, Lublin, Poland. 'Sub-Department of Veterinary Prevention and Avian Diseases, Institute of Biological Bases of Animal Diseases, Faculty of Veterinary Medicine, University of Life Sciences in Lublin, Lublin, Poland. ${ }^{4}$ Department of Food Technology, Faculty of Food Sciences, Warsaw University of Life Sciences (WULS-SGGW), Warsaw, Poland.

Received: 17 December 2015 Accepted: 21 August 2016

Published online: 26 August 2016

\section{References}

1. Criado E, Sánchez M, Ramírez J, Arguis P, de Caralt TM, Perea RJ, et al. Pulmonary sarcoidosis: typical and atypical manifestations at high-resolution CT with pathologic correlation. Radio Graphics. 2010;30(6):1567-86.

2. Newman LS, Rose CS, Bresnitz EA, Rossman MD, Barnard J, Frederick M, et al. A case control etiologic study of sarcoidosis: environmental and occupational risk factors. Am J Respir Crit Care Med. 2004;170(12):1324-30.

3. Cantwell AR. Bacteria in sarcoidosis and a rationale for antibiotic therapy in this disease. JOIMR. 2003;1(5):1 (http://www.joimr.org/phorum).

4. Chen ES, Moller DR. Etiology of sarcoidosis. Clin Chest Med. 2008:29(3):365-77.

5. Hui AWH, Lau HW, Chan THT, Tsui SKW. The human microbiota: a new direction in the investigation of thoracic diseases. J Thorac Dis. 2013:5 Suppl 2:S127-31.

6. Ivanov II, Littman DR. Modulation of immune homeostasis by commensal bacteria. Curr Opin Microbiol. 2011;14(1):106-14.

7. Rogers GB, Shaw D, Marsh RL, Carrol MP, Serisier DJ, Bruce KD. Respiratory microbiota: addressing clinical questions, informing clinical practice. Thorax. 2015;70:74-81

8. Piccolo M, De Angelis M, Lauriero G, Montemurno E, Di Cagno R, Gesualdo $L$, et al. Salivary microbiota associated with immunoglobulin A nephropathy. Microb Ecol. 2015;70(2):557-65

9. Hilty M, Burke C, Pedro H, Cardenas P, Bush A, Bossley C, et al. Disordered microbial communities in asthmatic airways. PLoS One. 2010;5(1):e8578. doi: 10.1371/journal.pone.0008578.

10. Sekirov I, Russell SL, Antunes CL, Finlay BB. Gut microbiota in health and disease. Physiol Rev. 2010;90(3):859-904

11. Bosch AATM, Biesbroek G, Trzcinski K, Sanders EAM, Bogaert D. Viral and bacterial interactions in the upper respiratory tract. PLoS Pathog. 2013;9(1):e1003057.

12. Cerquetti M. Molecular typing in bacterial infections Haemophilus spp. In: de Filippis I, McKee ML, editors. Molecular typing in bacterial infections. New York: Humana Press; 2013. p. 193-210. 
13. Nørskov-Lauritsen N. Classification, identification, and clinical significance of Haemophilus and Aggregatibacter species with host specificity for humans. Clin Microbiol Rev. 2014;27(2):214-40.

14. Kilian M. Haemophilus. In: Murray PR, Baron EJ, Jorgensen JH, Landry ML, Pfaller MA, editors. Manual of clinical microbiology. Washington: American Society of Microbiology; 2007. p. 636-48.

15. Middleton AM, Dowling RB, Mitchell $J$, Watanabe S, Rutman A, Pritchard K, et al. Haemophilus parainfluenzae infection of respiratory mucosa. Respir Med. 2003;97(4):375-81.

16. Hill SL, Mitchell JL, Stockley RA, Wilson R. The Role of Haemophilus parainfluenzae in COPD. Chest. 2000;117(5, suppl 1):293S.

17. García-Cobos S, Moscoso M, Pumarola F, Arroyo M, Lara N, Pérez-Vázquez $M$, et al. Frequent carriage of resistance mechanisms to $\beta$-lactams and biofilm formation in Haemophilus influenzae causing treatment failure and recurrent otitis media in young children. J Antimicrob Chemother. 2014; 69(9):2394-9.

18. Bjarnsholt T. The role of bacterial biofilms in chronic infections. APMIS. 2013; 121(suppl):1-51.

19. Starner TD, Zhang N, Kim G, Apicella A, McCray PB. Haemophilus influenzae forms biofilms on airway epithelia: implications in cystic fibrosis. Am J Respir Crit Care Med. 2006:174(2):213-20.

20. Cullen L, McClean S. Bacterial adaptation during chronic respiratory infections. Pathogens. 2015:4:66-89.

21. Burmølle M, Thomsen TR, Fazli M, Murree-Allen K, Hensley MJ, Saunders NA, et al. Biofilms in chronic infections - a matter of opportunity - monospecies biofilms in multispecies infections. FEMS Immunol Med Microbiol. 2010;59(3):324-36.

22. Gilley RP, Orihuela CJ. Pneumococci in biofilms are non-invasive: implications on nasopharyngeal colonization. Front Cell Infect Microbiol. 2014:4:163. doi:10.3389/fcimb.2014.00163.

23. Centers for Disease Control and Prevention (CDC). Active bacterial core surveillance $(A B C S)$ report, emerging infections program network, Haemophilus influenzae 2010. 2012. Available at: http://www.cdc.gov/abcs/ reports-findings/survreports/hib10.html.

24. Kosikowska U, Stępien-Pyśniak D, Ożga D, Wernicki A, Malm A. Identification of Bacillus spp. colonizing the nasal mucosa of healthy adults living in the suburban area using the matrix-assisted laser desorption-ionization time-offlight mass spectrometry (MALDI-TOF MS) system. Curr Issues Pharm Med Sci. 2014:27(3):137-41.

25. Clinical and Laboratory Standards Institute (CLSI). Performance standards for antimicrobial susceptibility testing; twenty-fourth informational supplement; M100-S24E. Wayne: Clinical and Laboratory Standards Institute; 2014

26. Kosikowska U, Korona-Głowniak I, Niedzielski A, Malm A. Nasopharyngeal and adenoid colonization by Haemophilus influenzae and Haemophilus parainfluenzae in children undergoing adenoidectomy and the ability of bacterial isolates to biofilm production. Medicine. 2015;94:pe799. doi:10. 1097/MD.0000000000000799

27. Stepanović S, Vukovic D, Dakic I, Savic B, Svabic-Vlahovic M. A modified microtiter-plate test for quantification of staphylococcal biofilm formation. J Microbiol Methods. 2000:40:175-9.

28. Arnold DF, Wiggins J, Cunningham-Rundles C, Misbah SA, Chapel HM. Granulomatous disease: Distinguishing primary antibody disease from sarcoidosis. Clin Immunol (Orlando, Fla). 2008;128(1):18-22.

29. Buckley CE, Dorsey FC. A comparison of serum immunoglobulin concentrations in sarcoidosis and tuberculosis. Ann Intern Med. 1970;72:37-42.

30. Buckley CE, Trayer HR. Serum IgD concentrations in sarcoidosis and tuberculosis. Clin Exp Immunol. 1972;10:257-65.

31. Tavares CSMQM, Bravo Junior WL, Alves Leite JL. Analyze the levels of immunoglobulins lgG and IgM in elderly and youngs. Int J Immunol Immunother. 2015;2:1.

32. Cagatay T, Bilir M, Gulbaran M, Papila C, Cagatay P. The immunoglobulin and complement levels in the active pulmonary sarcoidosis. Kobe J Med Sci. 2003:49:99-106.

33. Drent M, Wirnsberger RM, de Vries J, van Dieijen-Visser MP, Wouters EF, Schols AM. Association of fatigue with an acute phase response in sarcoidosis. Eur Respir J. 1999;13(4):718-22.

34. Segal LN, Rom WN, Weiden MD. Lung microbiome for clinicians. New discoveries about bugs in healthy and diseased lungs. Ann Am Thorac Soc. 2014;11(1):108-16.

35. Kelly DM. Endotoxin up-regulates interleukin-18: potential role for gramnegative colonization in sarcoidosis. Am J Respir Crit Care Med. 2005; 172(10):1299-307.
36. King P. Haemophilus influenzae and the lung (Haemophilus and the lung). Clin Transl Med. 2012:1:10.

37. Rhind GB, Gould GA, Ahmad F, Croughan MJ, Calder MA. Haemophilus biotypes in respiratory disease. Thorax. 1987:42:151-2.

38. Taylor DC, Cripps AW, Clancy RL, Murree-Allen K, Hensley MJ, Saunders NA, et al. Biotypes of Haemophilus parainfluenzae from the respiratory secretions in chronic bronchitis. J Med Microbiol. 1992;36(4):279-82.

39. Watson KC, Kerr EJ, Hinks CA. Distribution of biotypes of Haemophilus influenzae and $\mathrm{H}$. parainfluenzae in patients with cystic fibrosis. J Clin Pathol. 1985;38(7):750-3.

40. Carlet J, Jarlier V, Harbarth S, Voss A, Goossens H, Pittet D. Ready for a world without antibiotics? The Pensières Antibiotic Resistance Call to Action Antimicrob Resist Infect Control. 2012;1:11.

41. Garcia-Cobos S, Arroyo M, Campos J, Pérez-Vázquez M, Aracil B, Cercenado

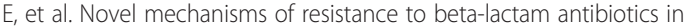
Haemophilus parainfluenzae: beta-lactamase-negative ampicillin resistance and inhibitor-resistant TEM beta-lactamases. J Antimicrob Chemother. 2013; 68(5):1054-9.

42. Thomas CM, Nielsen KM. Mechanisms of, and barriers to, horizontal gene transfer between bacteria. Nat Rev Microbiol. 2005;3(9):711-21.

43. Pfeifer $Y$, Meisinger I, Brechtel K, Grobner S. Emergence of a multidrug-resistant Haemophilus influenzae strain causing chronic pneumonia in a patient with common variable immunodeficiency. Microb Drug Resist. 2013;19(1):1-5.

44. Tinguely R, Seiffert SN, Furrer H, Perretenb V, Droza S, Endimiania A. Emergence of extensively drug-resistant Haemophilus parainfluenzae in Switzerland. Antimicrob Agents Chemother. 2013:57(6):2867-9.

45. Tristram SG, Pitout MJ, Forward K, Campbell S, Nichols S, Davidson RJ. Characterization of extended-spectrum beta-lactamase-producing isolates of Haemophilus parainfluenzae. J Antimicrob Chemother. 2008;61:509-14.

46. Gromkova RC, Mottalini TC, Dove MG. Genetic transformation in Haemophilus parainfluenzae clinical isolates. Curr Microbiol. 1998;37(2):123-6.

47. Søndergaard A, Witherden EA, Nørskov-Lauritsen N, Tristram SG. Interspecies transfer of the penicillin-binding protein 3-encoding gene fts/ between Haemophilus influenzae and Haemophilus haemolyticus can confer reduced susceptibility to beta-lactam antimicrobial agents. Antimicrob Agents Chemother. 2015;59:4339-42.

48. Witherden EA, Bajanca-Lavado MP, Tristram SG, Nunes A. Role of interspecies recombination of the $\mathrm{ftsl}$ gene in the dissemination of altered penicillin-binding-protein-3-mediated resistance in Haemophilus influenzae and Haemophilus haemolyticus. J Antimicrob Chemother. 2014;69:1501-9.

49. Moxon ER, Sweetman WA, Deadman ME, Ferguson DJ, Hood DW. Haemophilus influenzae biofilms: hypothesis or fact? Trends Microbiol. 2008:16(3):95-100.

50. Swords WE. Nontypeable Haemophilus influenzae biofilms: role in chronic airway infections. Front Cell Infect Microbiol. 2012;25(2):97. doi:10.3389/ fcimb.2012.00097.

51. Yonker LM, Cigana C, Hurley BP, Bragonzi A. Host-pathogen interplay in the respiratory environment of cystic fibrosis. J Cyst Fibros. 2015;14(4):431-9.

52. Clancy RL, Dunkley ML. Oral non-typable Haemophilus influenzae enhances physiological mechanism of airways protection. Clin Exp Immunol. 2010; 161(1):127-33.

\section{Submit your next manuscript to BioMed Central and we will help you at every step:}

- We accept pre-submission inquiries

- Our selector tool helps you to find the most relevant journal

- We provide round the clock customer support

- Convenient online submission

- Thorough peer review

- Inclusion in PubMed and all major indexing services

- Maximum visibility for your research

Submit your manuscript at www.biomedcentral.com/submit 